VI.-Frangulin.

By T. E. Thorpe, F.R.S., and H. H. Robinson, M.A.

THe constituents of the bark of the Alder Buckthorn (Rhamnus irangula), and more especially the yellow colouring matters that can be got from it, have occupied the attention of several chemists since the beginning of the century. Prior to 1857, no ultimate analyses of these colouring matters were made, although the substances obtainable from the bark had been frequently described. Gerber, in 1828 (Brande's Archiv. f. Pharm., 26, 1), published a proximate analysis of the bark, and among the substances enumerated was a yellow resinous colouring matter, which with alkalies gave a dark-red colour. Binswanger, in 1850, published a work on the constituents of the bark (Pharm. Studien über $R$. frangula und cathartica. München; also in Buchner's Repertorium $f$. Pharm. [3], 4, 47); among these he mentions a yellow colouring matter which he states Buchner had examined and named Rhamno-Xanthin. Buchner's work was not published until some years later, namely, in 1853 (Annalen, 87, 218); he had noticed that the paper in which some of the root-bark had been wrapped was coloured yellow, and that the inner surface of the bark was corered with golden-yellow crystals. He prepared some of the substance, examined its properties, and described its points of resemblance and dissimilarity to chrysophanic acid. In a later paper (Zeitschrift für Chem., 1865, 699), he described some yellowish-red, needle-shaped crystals he got from Rhamno-Xanthin by sublimation, but gave no analyses.

Winckler (Archiv. der Pharm., 1856, 335), Phipson (Compt. rend., 47, 153), Salm Horstmar (Pogg. Ann., 109, 539), and Enz (Viertel- 
jahrschrift für Pharm., 16, 106) have also treated of these yellow colouring matters.

Casselmann, in 1857 (Annalen, 104, 77), was the first to publish an ultimate analysis of a yellow colouring matter got from $R$. frangula. This substance he named Frangulin, considering that Buchner's name Rhamno-Xanthin was liable to be confused with Xantho-rhamnin, a substance Kane had obtained from $R$. cathartica and tinctoria. He used ammonia-water to extract it from the bark, and describes it as forming lemon-yellow, crystalline masses with a slight silky lustre and as appearing under the microscope in bright-yellow, transparent, square tables. He gives the melting point as about $249^{\circ}$. He made three analyses of frangulin prepared by different methods and dried at $100^{\circ}$; the mean of these analyses was, carbon $57 \cdot 19$ per cent. and hydrogen 4.98 per cent., from which he deduced the formula $\mathrm{C}_{6} \mathrm{H}_{6} \mathrm{O}_{3}$ (new notation). He examined the action of fuming nitric acid on frangnlin, and concluded that it yielded oxalic acid and a nitroderivative ; this he analysed, together with its silver and copper salts, and assigned to it the formula $\mathrm{C}_{20} \mathrm{H}_{10} \mathrm{O}_{8}\left(\mathrm{NO}_{2}\right)_{5}+\frac{1}{2} \mathrm{H}_{2} \mathrm{O}$.

Kubly, in 1866 (Pharm. Zeitschrift für Russland, 5, 160), obtained a substance from the bark which he named Avornin, and which he found to be a glucoside, yielding on hydrolysis, sugar, an acid which he called avornic acid, and an amorphous resin.

Faust repeated his work and found that avornin was impure frangulin, but to Kubly is due the discovery of the glucosidal nature of frangulin.

Faust, in 1872, published a paper (Annalen, 165, 229) on frangulin and frangulic acid : he prepared a small quantity of frangulin, using alcohol to extract it from the bark; he did not see the square tables mentioned by Casselmann, and found that its melting point was $226^{\circ}$, also that when boiled with hydrochloric acid it split up into frangulic acid and sugar; but he had not enough frangulin either to make a quantitative hydrolysis or an analysis. He accepted Casselmann's analysis, and multiplying $\mathrm{C}_{6} \mathrm{H}_{6} \mathrm{O}_{3}$ by $3 \frac{1}{3}$, gave $\mathrm{C}_{20} \mathrm{H}_{20} \mathrm{O}_{10}=\mathrm{C}_{14} \mathrm{H}_{8} \mathrm{O}_{4}$ $+\mathrm{C}_{6} \mathrm{H}_{12} \mathrm{O}_{6}$ as the equation representing its hydrolysis. He prepared frangulic acid directly from the bark, using boiling caustic soda solution; he found that on drying this at $120^{\circ}$ it lost 6.07 per cent. in one case and 6.4 per cent. in another, and when thus dried gave carbon 67.26 per cent. and hydrogen 4 per cent. as a mean of five analyses: but in these the carbon varied from 66.78 to 67.91 per cent. $\mathrm{He}$ assigned the formula $2 \mathrm{C}_{14} \mathrm{H}_{8} \mathrm{O}_{4}, 3 \mathrm{H}_{2} \mathrm{O}$ to the undried substance and $2 \mathrm{C}_{14} \mathrm{H}_{8} \mathrm{O}_{4}, \mathrm{H}_{2} \mathrm{O}$ to it when dried at $120^{\circ}$. He next dried a sample at $180^{\circ}$, when it lost 10.97 per cent. $\left(2 \mathrm{C}_{14} \mathrm{H}_{8} \mathrm{O}_{4}, 3 \mathrm{H}_{2} \mathrm{O}\right.$ in losing $3 \mathrm{H}_{2} \mathrm{O}$ would give up 10.11 per cent.), and on analysing the product thus dried he got carbon 70.33 per cent. and hydrogen $3 \cdot 67$ per cent. 
$\left(\mathrm{C}_{14} \mathrm{H}_{3} \mathrm{O}_{4}\right.$ would give carbon 70 per cent. and hydrogen $3 \cdot 3$ per cent. $)$. He further prepared and analysed a bromine-derivative and an acetylderivative of frangulic acid. By distilling frangulic acid with zinc-dust he obtained anthracene, and concluded that the acid was dihydroxyanthraquinone and therefore an isomer of alizarin.

Liebermann and Waldstein were the next authors to treat of the yellow colouring matter got from $R$. frangula (Berichte, 1876, 1775); they did not prepare frangulin, but examined a colouring matter got from the bark by means of caustic soda solution. They made five analyses of this; in two cases drying the substance at $190^{\circ}$, and in one case subliming it, crystallising the sublimate from alcohol and drying at $150^{\circ}$. The mean of their analyses was, carbon 67.1 per cent. and bydrogen 4 per cent., the carbon ranging from $66 \cdot 7$ to $67 \cdot 2$ per cent. ; they therefore assigned the formula $\mathrm{C}_{15} \mathrm{H}_{10} \mathrm{O}_{5}$ to the substance. They prepared and analysed an acetyl-derivative and made a distillation of the colouring matter with zinc-dust, obtaining a mixture of anthracene and methylanthracene, resembling that obtained from emodin and from chrysophanic acid, and giving on oxidation anthraquinonecarboxylic acid. They compared the properties of the colouring matter and its behaviour with various reagents with those of emodin, and they found the melting point of both to be $257^{\circ}$. Finally, they concluded that the colouring matter they examined was identical with emodin. As regards Faust's frangulic acid, they considered it to be probably a different substance, and that possibly it and emodin may occur jointly in the bark and mutually replace one another as alizarin and purpurin do in madder. They suggest $\mathrm{C}_{21} \mathrm{H}_{20} \mathrm{O}_{10}+\mathrm{H}_{2} \mathrm{O}=\mathrm{C}_{15} \mathrm{H}_{10} \mathrm{O}_{5}+\mathrm{C}_{6} \mathrm{H}_{12} \mathrm{O}_{6}$ as the equation representing the hydrolysis of frangulin.

Keussler, who published his paper in 1878 (Pharm. Zeitschrift für Russland, 17, 257), did not prepare frangulin, but used caustic soda and sodium carbonate in his operations on the bark, and obtained a substance having the same external appearances as the frangulic acid of Faust and the emodin of Liebermann and Waldstein. $\mathrm{He}$ came to the conclusion, however, that this was not emodin, but contained an additional $\mathrm{CH}_{2}$ group, and was trihydroxyethyl- or trihydroxiydimethylanthraquinone. He made five analyses of it dried at $180^{\circ}$, and obtained carbon 67.54 per cent. and hydrogen 4.38 per cent. as a mean result, the carbon varying from 67.41 to 67.69 per cent. $\left(\mathrm{C}_{16} \mathrm{H}_{12} \mathrm{O}_{5}\right.$ corresponds to carbon 67.6 per cent. and hydrogen 4.2 per cent.). On distilling it with zinc-dust, he obtained and analysed a mixture of anthracene and methylanthracene, a considerable evolution of gas taking place during the distillation, possibly due to the decomposition of dimethylanthracene. He also prepared and analysed a nitro-derivative and its silver salt. 
The only analysis of frangulin since that of Casselmann was made by Schwabe (Arch. der Pharm., 1888, 26, 569), who assigned to it the formula $\mathrm{C}_{21} \mathrm{H}_{20} \mathrm{O}_{9}$; he hydrolysed it quantitatively, and obtained from it a substance insoluble in water, which he analysed and found to be emodin, and a substance soluble in water which reduced Fehling's solution. He suggests that the latter is the rhamnodulcite described by Liebermann, and that the equation for the hydrolysis is $\mathrm{C}_{21} \mathrm{H}_{20} \mathrm{O}_{9}+\mathrm{H}_{2} \mathrm{O}=\mathrm{C}_{15} \mathrm{H}_{10} \mathrm{O}_{5}+\mathrm{C}_{6} \mathrm{H}_{12} \mathrm{O}_{5}$. In previous communications one of us, in conjunction with Mr. T. H. Greenall (Trans., 1887, 51, 52 ), and subsequently in conjunction with Dr. W. T. Smith (Trans., $1888,53,171)$, has shown that morindin, the characteristic colouring matter of A'l, the root-bark of Morinda citrifolia, also yields on hydrolysis a trihydroxymethylanthraquinone, $\mathrm{C}_{15} \mathrm{H}_{10} \mathrm{O}_{5}$, which, however, seems not to be identical with emodin. In view, therefore, of the discrepancies in the statements of Faust, of Liebermann and Waldstein, and of Keussler, it became of interest to determine (1) what was the true composition of the frangulin, and what was the real nature of the products of its hydrolysis, and (2), if a trihydroxymethylanthraquinone should turn out to be one product of the hydrolysis, as Liebermann and Waldstein, and also Schwabe assert, whether this body was identical with morindon.

\section{Preparation of Frangulin.}

The preparation of frangulin from the bark is a somewhat troublesome and tedious operation, for not only is it present in very small quantities, but it is accompanied by plant fat and resinous substances, from which it is not easily separated. The method we adopted was first to remove the plant fat by repeatedly extracting the crushed bark with low-boiling petroleum, which dissolves very little except the fat and chlorophyll, and then to extract the residue with methylated spirit, the extraction being continued until the liquid running off contained but little colouring matter.

These extractions were performed in an apparatus, Fig. 1, designed on Soxhlet's plan, but modified so as to suit the large quantities of material dealt witb. It consisted of a cylindrical tin can, $E, 10$ inches in diameter and $\mathrm{J} 7$ inches in height, provided with a removable conical top, $C$, which could be secured to the can by means of a stout brass flange which was pressed by means of a number of clamps to a similar flange attached to the top of the cylinder. A washer cut out of sheet indiarubber and placed between the two flanges kept the apparatus air-tight when the clamps were screwed up. The charge of bark, weighing 14 lbs., was contained in a muslin bag and rested on a false bottom made of thick tin-plate, perforated with holes and sup- 
ported by legs at a height of about $1 \frac{1}{2}$ inches from the bottom of the can. In the side of the can and close to the bottom was a tin tubulure $a$, giving access to the space below the false bottom. Into this, by means of a cork, the end of a tube, $s$, was fitted which rose vertically outside the can to a point a little below the flanges and then bent over and acted as a syphon. To avoid too great rigidity, there was a junction in the tube at $b$. At the top of the conical lid was a tubulure, into which a glass $T$-piece was fitted. The syphon led to a bottle-shaped copper vessel, $R$, of about four gallons capacity, in which the petroleum or methylated spirit was boiled. The vapour of the solvent was conducted by a wide-bent glass tube, $t$, up to the side branch of the $T$-piece and through it into a reflux condenser which was joined to the upper extremity $c$ of the T-picce. The glass tube $t$ was wrapped round with strips of woollen cloth to prevent con-

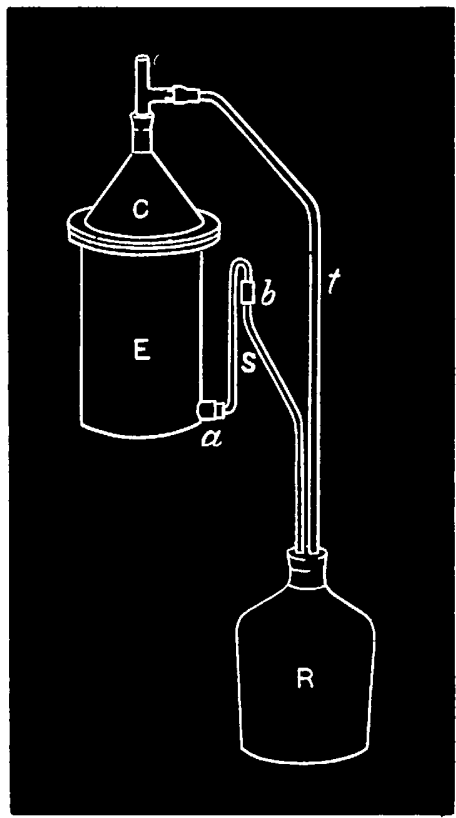

FIG. 1.

densation occurring in it. By employing this apparatus, the same quantity of liquid was made to serve for numerous extractions, as it was syphoned off into the copper can as soon as the tin was full, and was then boiled off again, passed to the condenser, and returned as fresh solvent to the tin. Both the extracting tin and the copper can were surrounded by water-baths and could be heated to suitable temperatures. 
The methylated-spirit extract on standing for two days deposited a considerable quantity of dark-brown resinous matter; it was filtered, and to the filtrate a solution of lead acetate in methylated spirit was added in order to remove tannin, the brown precipitate thus produced was filtered off, and through the filtrate a current of sulphuretted hydrogen was passed to throw down the lead present. After separating the lead sulphide by filtration, the solution was put aside for five weeks, and at the end of that time it was found to have deposited some frangulin, which separates from such impure liquids in characteristic little orange-red spheres of some $\frac{1}{4} \mathrm{~mm}$. or so in diameter. This deposit was purified by heating with spirit, which dissolved some brown impurities and was poured off; the residue was then recrystallised from methylated spirit, of which a large quantity was required to effect solution. This preparation, which will be denoted by $A$ for reference, amounted to $2 \cdot 0$ grams and was of an orangeyellow colour.

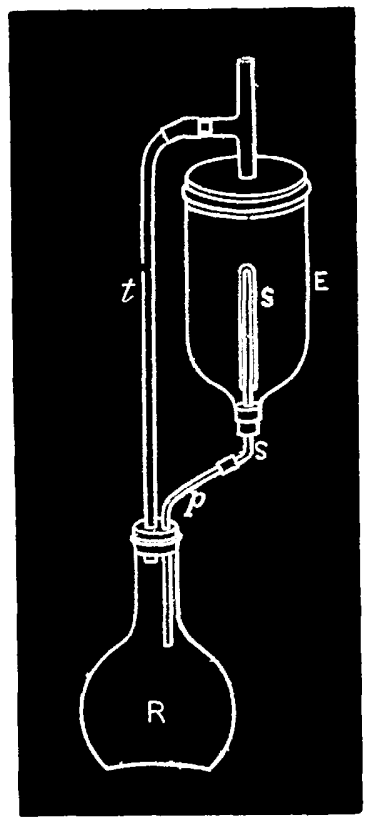

FIG. 2.

The liquid which had deposited the frangulin spheres was next evaporated to dryness with addition of calcium sulphate, which was added in order to get a residue that could be submitted to extraction with ether ; it would otherwise have given a brown, pitch-like mass. The residue obtained was further mixed with fragments of pumice 
to facilitate the extraction, which was performed in a modified form of King's extractor, Fig. 2 (Chem. News, 1888, 57, 235), constructed out of an inverted bell-glass, $E$. This was closed at the bottom by a cork through which a vertical tube, $s$, passed. This tube was ground off at an angle at its upper extremity, and over it was inverted a somewhat wider tube closed at its upper end and reaching nearly bat not quite down to the cork at the bottom. A plug of glass wool was placed on the cork, and then the residue mixed with fragments of pumice was packed in, taking care to have a column of pumice fragments round the centre tubes. The wide end of the bell-glass was closed with a large cork through which a glass $T$-tube passed. This cork was coated with plaster of Paris to prevent escape of ether. The lower end of the tube $s$ was bent and passed for a short distance into the end of a slightly wider tube, $p$, and the joint was made good with a piece of indiarabber tubing. The tube $p$ led through the cork of a flask, $R$, in which the ether was heated. The vapours of the ether were conducted up a wide tube, $t$, to the side arm of the $T$-tube, and thence to a reflux condenser connected to the upper end of the T-tube. The condensed ether flowed into the bell-glass, and when it rose above the top of the tube $s$, it was syphoned back into the flask $R$ again; thus the operation went on automatically, as in the case of the large extractor.

Some of the extracts obtained deposited fairly pure frangulin; others were so impure that but little frangulin could be got from them. The best extracts were obtained when the amount of calcium sulphate added was sufficient to produce a residue that could be crumbled between the fingers.

The frangulin thus obtained, together with about half a gram obtained in preparing $A$, but which wanted another purification, was recrystallised from alcohol and gave 2.7 grams (preparation $B$ ).

Besides the above two preparations, a little more frangulin was got from the calcium sulphate residue and from various mother-liquors, making the total quantity obtained from $14 \mathrm{lbs}$. of the bark about $5 \frac{1}{2}$ grams, a yield equivalent to 0.09 per cent.

Frangulin is an orange-yellow powder which under the microscope has a crystalline appearance, best seen by reflected light; when in suspension in a liquid, or when a mass has dried in a cake, it often exhibits a silky lustre. It is not very soluble in hot alcohol and is still less soluble in cold, separating as the solution cools; the cold alcoholic solution, however, has a distinctly yellow colour. The presence of a trace of alkali imparts a red tinge to its solutions. It melts at ahout $225^{\circ}$.

Composition.-The preparations A and B were now analysed; they had been placed over sulphuric acid in a vacuum to dry, and a 
portion of each was weighed out in a platinum boat and then dried at $120^{\circ}$ until the weight became constant.

I. 0.2099 gram of frangulin (preparation A), after drying at $120^{\circ}$ until constant, became 0.2061 gram, a loss equivalent to 1.8 per cent., and then on combustion gave 0.4643 gram of $\mathrm{CO}_{2}$ and 0.0997 gram of $\mathrm{H}_{2} \mathrm{O}$.

II. $0 \cdot 1884$ gram of frangulin (preparation B), after drying at $120^{\circ}$ until constant, became $0 \cdot 1836$ gram, a loss equivalent to $2 \cdot 5$ per cent., and then on combustion gave 0.4115 gram of $\mathrm{CO}_{2}$ and 0.0862 gram of $\mathrm{H}_{2} \mathrm{O}$.

\section{Percentage Composition of Frangulin.}

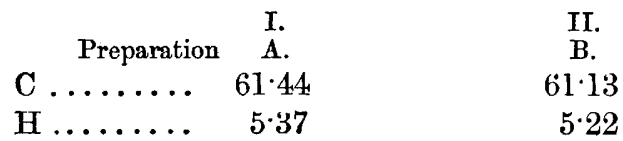

The agreement of the analyses of two independent preparations pointed to the substance being homogeneous, and not a mixture, and it will be seen that further analyses confirmed this.

\section{Hydrolysis.}

A preliminary experiment showed that when frangulin in solution in methylated spirit was boiled with the addition of aqueons hydrochloric acid, it was decomposed into a substance (which subsequently proved to be emodin) precipitated on diluting with water, and a substance which remained in solution and had the power of reducing Fehling's solution.

Quantitative hydrolyses of preparations A and B were next made. Weighed quantities of $\mathrm{A}$ and $\mathrm{B}$ were dried at $120^{\circ}$ until constant in weight, and then dissolved in alcohol, 10 c.c. of strong aqueous hydrochloric acid added, and the solution boiled for about 3 or 4 hours, using a reflux condenser. After the alcohol had been boiled off until the solution was reduced to a half or a third of its original bulk, it was largely diluted with water, which caused an orange-yellow precipitate to separate; evaporation was continued for some time in order to drive off all alcohol, and the precipitate was collected on a dried and weighed filter paper; it was then washed with water and dried at $120^{\circ}$ until constant. The filtrate was almost colourless, and considering the strong tinctorial power of the precipitated substance, practically all of it must have been separated by the treatment adopted.

I. 0.8457 gram of frangulin (preparation A), on drying at $120^{\circ}$ vOL. LYIJ. 
until constant, lost 0.0131 gram (equivalent to 1.55 per cent.). The resulting 0.8326 gram of dry frangulin on hydrolysis gave 0.5710 of product (emodin) insolnble in water.

II. Some frangulin (preparation B), after drying at $120^{\circ}$ until constant, weighed 0.7722 gram, and on bydrolysis gave 0.5146 gram of product (emodin) insoluble in water.

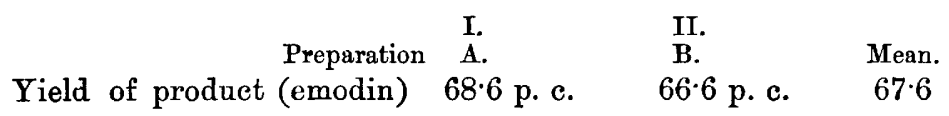

\section{Product of Hydrolysis insoluble in Water (Emodin).}

The product of the hydrolysis thrown down on diluting with water was of an orange colour, and under the microscope proved to be a mass of interlacing needles; it was much more soluble in alcohol than frangulin; with caustic soda solution, it gave a characteristic cherry-red colour.

The products from the hydrolyses of preparations A and B were separately crystallised from alcohol, and combustions were made of them after drying at $120^{\circ}$ until constant in weight.

I. 0.2200 gram of the product from the hydrolysis of frangulin (preparation A) after drying at $120^{\circ}$ until constant, became $0 \cdot 2086$, a loss equivalent to $5 \cdot 18$ per cent., and then on combustion gave 0.5076 gram of $\mathrm{CO}_{2}$ and 0.0723 gram of $\mathrm{H}_{2} \mathrm{O}$.

II. 0.1508 gram of the product from the hydrolysis of frangulin (preparation B) after drying at $120^{\circ}$ until constant, became $0 \cdot 1401$ gram, a loss equivalent to $7 \cdot 10$ per cent., and then on combustion gave 0.3430 gram of $\mathrm{CO}_{2}$ and 0.0500 gram of $\mathrm{H}_{2} \mathrm{O}$.

Some more frangulin was hydrolysed in the manner described above, but using a 10 per cent. solution of sulphuric acid in larger volume instead of the hydrochloric acid. The insoluble product obtained was crystallised from benzene, and an attempt was made to sublime it in a vacuum at a temperature of $240^{\circ}$, using a bath of diphenylamine. The sublimate, however, formed too slowly, so the substance was again crystallised from benzene, and used for making two analyses. It was first dried at $180^{\circ}$, but lost nothing by that treatment.

III. 0.2073 gram of the insoluble product, dried at $180^{\circ}$, gave on combustion 0.5000 gram of $\mathrm{CO}_{2}$ and 0.0701 gram of $\mathrm{H}_{2} \mathrm{O}$.

IV. $0 \cdot 2003$ gram of the insoluble product, dried at $180^{\circ}$, gave on combustion 0.4898 gram of $\mathrm{CO}_{2}$ and 0.0691 gram of $\mathrm{H}_{2} \mathrm{O}$. 
THORPE AND ROBINSON : FRANGULIN.

Percentage Composition of the Insoluble Product.

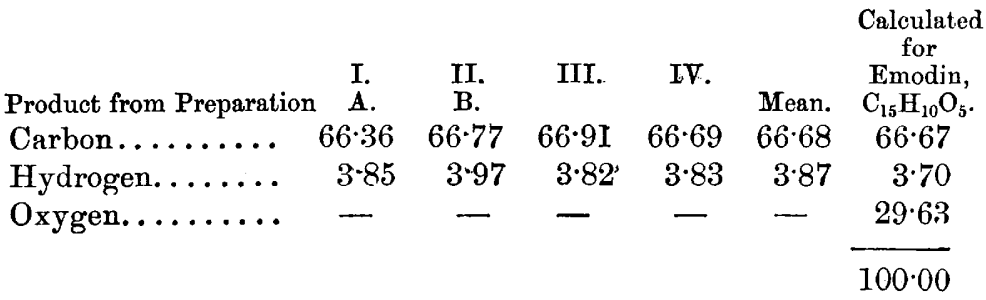

Thus the product of the hydrolysis has the same eomposition as emodin, as stated by Liebermann and Waldstein, and by Schwabe.

The product obtained from frangulin was compared side by side with some emodin obtained from rhubarb, which Dr. Hugo Müller had kindly furnished, in respect to its colour reactions with strong sulphuric acid and with strong potash solution, and the same cherryred colours were obtained from both specimens.

\section{Further Analyses of Frangulin.}

As the analyses published by Schwabe differed notably from those given on p. 45, we subjected our preparations to further treatment to remove any possible impurities, and then made other combustions, the results of which agreed with those first obtained.

Preparation B was twice recrystallised from alcohol, and then gave the following results :-

III. 0.2133 gram of frangulin, after drying at $120^{\circ}$ till constant, lost 0.0045 gram, equivalent to 2.11 per cent.; 0.2081 gram of the frangulin thus dried gave on combustion 0.4669 gram $\mathrm{CO}_{2}$ and 0.0994 gram $\mathrm{H}_{2} \mathrm{O}$.

IV. 0.2041 gram of frangulin, after drying at $120^{\circ}$ until constant, became 0.1997 gram, a loss equivalent to $2 \cdot 16$ per cent., and then on combustion gave 0.4485 gram $\mathrm{CO}_{2}$ and 0.0950 gram $\mathrm{H}_{2} \mathrm{O}$.

V. $0 \cdot 2540$ gram of frangulin, after drying at $120^{\circ}$ until constant, became 0.2485 gram, a loss equivalent to 2.17 per cent., and then on combustion gave 0.5567 gram of $\mathrm{CO}_{2}$ and 0.1176 gram of water.

Percentage Composition of Frangulin.

(Preparation B twice recrystallised from alcohol.)

\begin{tabular}{|c|c|c|c|}
\hline $\mathrm{C} \ldots \ldots$ & $\begin{array}{c}\text { III. } \\
61 \cdot 19\end{array}$ & $\begin{array}{c}\text { IV. } \\
61 \cdot 25\end{array}$ & $\begin{array}{c}\text { V. } \\
61 \cdot 10\end{array}$ \\
\hline$H \ldots \ldots$ & $5 \cdot 31$ & $5 \cdot 29$ & $5 \cdot 26$ \\
\hline
\end{tabular}


Another method of purifying it for analysis was next tried, and still the results proved to be the same as before. Portions of preparations $A$ and $B$, and of $B$ recrystallised, were mixed and warmed with ether, but not dissolved; filtered and washed with ether; then crystallised from alcohol and washed, first with ether and then with alcohol. Two analyses were made of the frangulin thus prepared.

VI. $0 \cdot 1543$ gram of frangulin, after drying at $120^{\circ}$ until constant, lost $0.0033 \mathrm{gram}$, equivalent to $2 \cdot 14$ per cent. 0.1501 of the frangulin thus dried gave on combustion 0.3366 gram of $\mathrm{CO}_{2}$ and 0.0721 gram of $\mathrm{H}_{2} \mathrm{O}$.

VII. $0 \cdot 1998$ gram of frangulin, after drying at $120^{\circ}$ until constant, lost 0.0055 gram, equivalent to 2.75 per cent. 0.1939 of the frangulin thus dried gave on combustion 0.4348 gram of $\mathrm{CO}_{2}$ and 0.0920 gram of $\mathrm{H}_{2} \mathrm{O}$.

(Preparations A and B mixed, treated with ether, and recrystallised.)

$$
\begin{aligned}
& \text { VI. VII. } \\
& \text { C } \ldots \ldots \ldots \ldots \ldots 606061 \cdot 16 \quad 61 \cdot 16 \\
& \mathrm{H} \ldots \ldots . \ldots \ldots . \quad 5 \cdot 34 \quad 5 \cdot 27
\end{aligned}
$$

Collecting these analyses together and taking the mean, it will be seen that they are quite concordant, and agree with the formula $\mathrm{C}_{22} \mathrm{H}_{22} \mathrm{O}_{9}-$

$$
\text { Percentage Composition of Frangulin. }
$$

I. II. III. IV. $\quad$ V. VI. VII. Mean. $\begin{gathered}\text { Calculated } \\ \text { for } \\ \mathrm{C}_{22} \mathrm{H}_{22} \mathrm{O}_{9} \text {. }\end{gathered}$

$$
\begin{array}{lrrrrrrrrr}
\text { C... } & 61 \cdot 444 & 61 \cdot 13 & 61 \cdot 19 & 61 \cdot 25 & 61 \cdot 10 & 61 \cdot 16 & 61 \cdot 16 & 61 \cdot 20 & 61 \cdot 40 \\
\text { H.. } & 5 \cdot 37 & 5 \cdot 22 & 5 \cdot 31 & 5 \cdot 29 & 5 \cdot 26 & 5 \cdot 34 & 5 \cdot 27 & 5 \cdot 29 & 5 \cdot 11 \\
\text { O.. } & - & - & - & - & - & - & - & 33 \cdot 51 & 33 \cdot 49 \\
& & & & & & & & \frac{100 \cdot 00}{100 \cdot 00}
\end{array}
$$

Schwabe found, as a mean of five analyses, the figures given below and assigns to frangulin the formula $\mathrm{C}_{21} \mathrm{H}_{20} \mathrm{O}_{9}-$

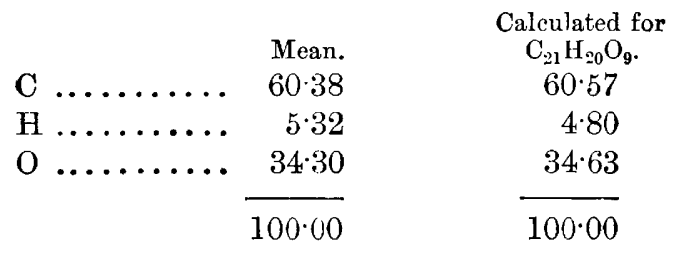

It will be noticed that the mean of Schwabe's analyses differs considerably from that of our analyses. The disparity may perhaps be 
due to a difference in the way of drying; our frangulin was in every case dried at $120^{\circ}$ till constant, losing about 2 per cent. in the process. Schwabe remarks that, on drying, frangulin lost no water of crystallisation, but does not state at what temperature he dried it. If our frangulin had contained $1 \frac{1}{2}$ per cent. of water when analysed, the figures would have been carbon $60 \cdot 28$, and hydrogen $5 \cdot 38$, whick are very close to those obtained by Schwabe.

\section{The Product of the Hydrobysis Soluble in Water.}

In order to determine the nature of the product soluble in water obtained by the hydrolysis of frangulin, the filtrate from the emodin obtained in hydrolysis I was concentrated to a small bulk, and it was heated with the addition of sodium acetate, phenylhydrazine bydrochloride, and water, and eraporated to dryness. The residue was treated with water, when a brown substance remained undissolved, and was collected; this proved to be insoluble in hot water, but dissolved in alcohol; on diluting the alcoholic solution, an orangeyellow precipitate with a brownish tinge separated, this was collected and dried, and its melting point found to be about $158^{\circ}$. Some phenylglucosazone was prepared for comparison, and was foand to be quite different from the osazone of the product from frangulin. The product in question is undoubtedly not glucose.

Owing to the small quantities of frangulin hydrolysed, our attempts to isolate the product from the filtrates obtained in the other hydrolyses were unsuccessful.

Conclusions:- - The results arrived at are:-

1. That frangulin is a glucoside of the formula $\mathrm{C}_{23} \mathrm{H}_{22} \mathrm{O}_{9}$, the term glucoside being used in its wider sense as including substances which on hydrolysis yield products capable of reducing. Fehling's solution.

2. That the products of its hydrolysis are emodin, identical with the emodin of rhubarb, and a compound which reduces Fehling's solution, but which is not glucose.

As the yield (67.6 per cent.) of emodin on hydrolysis was higher than the theoretical amount $\left(62 \cdot 8\right.$ per cent.) which $\mathrm{C}_{22} \mathrm{H}_{22} \mathrm{O}_{9}$ should yield, it was imaginable that the formula was really $\mathrm{C}_{21} \mathrm{H}_{20} \mathrm{O}_{9}$, and that the higher percentage of carbon obtained was due to the presence of free emodin as an impurity; hut this view was discarded, firstly, because the presence of 10 per cent. of free emodin would be required to raise the carbon from 60.58 to $61 \cdot 20$, and this could scarcely be present in each of the four samples that had received different treatment yet gave concordant figures; and, secondly, because the presence of 10 per cent. of emodin would have made the 
hydrogen 4.70 per cent., an amount differing widely from the 5.29 per cent. obtained.

We are engaged in preparing larger quantities of frangulin with a view of redetermining the yield on hydrolysis and of identifying the soluble product; but as we are unable to continue the investigation together we are now communicating this section to the Society, and the subject will be continued by one of us. 